\title{
Detecting and Locating Power Quality Issues by Implementing Wavelet Transform
}

\author{
Mohammad Asadi \\ Electricity Distribution \\ Company of Mazandaran \\ Sari, Iran
}

\author{
Mehrshad Noori Harikandeh \\ Electrical and Computer \\ Engineering Faculty \\ Islamic Azad University \\ Ghaemshahr, Iran
}

\author{
Mohammadreza Hamzenia \\ Electrical and Computer \\ Engineering Faculty \\ Islamic Azad University \\ Ghaemshahr, Iran
}

\begin{abstract}
Lack of power quality imposes many costs on large and small consumers every year. Therefore, considering the importance of power quality in today's industries, this article examines the issue of detection and location of various power quality issues. DWT discrete wavelet transform is investigated in this paper. The signals under the perturbations are written to the field and the start and end times of the perturbation are obtained and compared with the real time, and the accuracy of the measurements is confirmed by repetitions.
\end{abstract}

Keywords: flicker; power quality; voltage sag; voltage swell; wavelet transform

\section{INTRODUCTION}

The issue of power quality has been discussed since the beginning of the knowledge of electricity, but what was considered as electricity quality in the past, due to lack of sensitivity of consumers, their connection or disconnection. Today, the quality of electricity has become very important. This importance can be attributed to reasons such as the greater sensitivity of industrial loads, increased linear loads, increased use of small power plants and, most importantly, increased costs due to its absence [1-4]. Lack of power quality imposes a lot of costs on consumers, large and small, every year due to their load to voltage sensitivity. For example, many home appliances are damaged by these annual disturbances. As a result, identifying, monitoring, and controlling these disturbances with phasor measurement units (PMUs) can prevent significant damages [5]. Although the voltage stability, in the industry has been discussed for several years, there are still no standardized definitions in some areas. According to the IEEE1159 standard, power quality disturbances are classified into seven groups: transients [6], long-term voltage changes, short-term voltage changes [5], waveform distortions, voltage imbalances, flicker, and frequency changes, each of which in turn follows Branches are divided [7].

Voltage sags and voltage surges are classified in the group of short-term voltage and harmonic changes in the group of waveform distortions [8]. These perturbations have been studied in this work. Various tools have been used to analyze power quality perturbations. One of the tools that is becoming more and more popular is the Wavelet Converter [9]. Wavelet converter is a mathematical tool that scans data, functions, or operators into different frequency components and then studies each component with resolution according to its scale. For example, in signal analysis, wavelet transform allows us to view the time history in terms of the frequency components of the signal [10]. This article provides an overview of wavelet transform and applications of wavelet transform in power systems.

\section{WAVELET TRANSFORM AS A DETECTION AND LOCATION TOOL}

Most current methods for detecting power quality perturbations have their limitations and are implemented directly in the time field. In this paper, a proposal for detection and localization of perturbations based on orthogonal wavelet transform is presented in which time-scale field detection is performed [11]. As will be shown in the next section, this proposition is useful in detecting a wide range of power quality perturbations such as rapid voltage fluctuations, short-term voltage changes, and harmonic perturbations [12].

The detection method is almost straightforward. The given waveform is transmitted to the time-scale field using Multiple Signal Detection (MSD) analysis. Normally, single or double scale signal analysis is appropriate to distinguish perturbations from their backgrounds, because the decomposed signals at lower scales (higher frequencies) have high temporal location. In other words, high-scale signal analysis is not necessary because it gives poor temporal positioning. Suppose we have a special type of mother wavelet with L filter coefficient, $h(n)$ and $g(n)$, which form a family of wavelet functions $\phi(t)$ and scale functions $\psi(\mathrm{t})$, respectively [13].

$$
\begin{aligned}
& \varphi(t)=\sqrt{2} \sum_{n} h(n) \Phi(2 t-n) \\
& \Psi(t)=\sqrt{2} \sum_{n} g(n) \Psi(2 t-n)
\end{aligned}
$$

As a result, the process of detection and localization is a set of processes of convolution and dissimilation at the corresponding scale. In scale one, the electrical power signal $\mathrm{c}_{0}(\mathrm{n})$ with $\mathrm{N}$ sampling point is decomposed into two other signals. $c_{1}(n)$ and $d_{1}(n)$ are defined as follows:

$$
\begin{aligned}
& c_{1}(n)=\sum_{k} h(k-2 n) c_{0}(k) \\
& d_{1}(n)=\sum_{k} g(k-2 n) c_{0}(k)
\end{aligned}
$$


The signal $c_{1}(n)$ is the smoothed model of the original signal $c_{0}(n)$ while the model $d_{1}(n)$ is the detail of the main signal which is in the form of wavelet transform coefficients (WTCs) on a scale of one. These coefficients provide detection information. In cases of power quality perturbations, whenever perturbations occur in a given sine waveform, WTCs are exclusively larger than their adjacent coefficients [14]. Transform of wavelets to signals with sensitive disturbances. But its behavior is "blind" to fixed behavior signals (i.e., a $60 \mathrm{~Hz}$ sine waveform) [15]. By considering this process, one can assume that the physical understanding of detection and location described in (3) and (4) is as follows:

$$
\begin{aligned}
& c_{1}(n)=\int f(t) \varphi_{1, n}(t) d t=\frac{1}{\sqrt{2}} \int f(t) \varphi\left(\frac{t}{2}-n\right) d t \\
& d_{1}(n)=\int f(t) \psi_{1, n}(t) d t=\frac{1}{\sqrt{2}} \int f(t) \psi\left(\frac{t}{2}-n\right) d t
\end{aligned}
$$

where:

$$
f(t)=\sum_{n} c_{0}(n) \varphi(t-n)=\sum_{n} c_{0}(n) \varphi_{0, n}(t)
$$

In (7) it can be considered as a "dummy signal" generated by a linear combination with a scale function at zero scale. So, any disturbance in will be well manifested. By placing (1) and (2) in (5) and (6) we will have:

$$
\begin{aligned}
& c_{1}(n)=\int f(t) \sum_{k} h(k) \varphi(t-2 n-k) d t \\
& d_{1}(n)=\int f(t) \sum_{k} g(k) \varphi(t-2 n-k) d t
\end{aligned}
$$

It can be inferred from Equation (8) that $\mathrm{c}_{1}(\mathrm{n})$ is the smoothed model of the main signal $c_{0}(n)$, because $h(n)$ has a lowfrequency response. Whereas from (9) it is obvious that contains only frequency components higher than the signal $\mathrm{f}(\mathrm{t})$ because $\mathrm{g}(\mathrm{n})$ has a high-pass filter response. This explains why the analysis of wavelet transform is sensitive to signals with large perturbations but is "blind" to perturbations of constant behavior. In practice, it is not necessary to construct $\mathrm{f}(\mathrm{t})$, but it is useful in understanding the physical process of detection and location as expressed in (5) and (6). In fact, the signals are obtained directly from Equations (3) and (4). This greatly simplifies the detection and location process [16]. The detection process for the second scale $c_{1}(n)$ starts from the signal in which this signal can be considered as a new $\mathrm{c}_{0}(\mathrm{n})$. The above process is repeated. Because wavelet and scale functions become wider as the scale increases, temporal location is lost. It is suggested that higher scale decomposition is not necessary. As long as the detection of disturbances in power systems is desired, two-scale signal analysis of the original signal is sufficient to detect and locate the disturbances [17].

\section{SIMULATION AND RESULTS}

\subsection{Data Production}

Table 1 can be used to generate power quality phenomena and its parameters can be controlled. This work focuses on the phenomena of voltage dip, voltage swell, harmonic, harmonic and flicker. The length and amplitude of perturbations are defined by IEEE1159.
The voltage flicker can be seen as a carrier wave that changes the amplitude modulation at a frequency of $30 \mathrm{~Hz} \sim 1 \mathrm{kHz}$. The flicker signal $\mathrm{u}(\mathrm{t})$ is expressed as follows:

$$
u(t)=V_{m}[1+m \cos (\Omega t)] \cos \left(\omega_{0} t\right)
$$

where, $V_{m}$ is voltage amplitude at power frequency, $\omega_{0}$ is the angular frequency of the carrier wave, $\mathrm{m}$ is the amplitude of the carrier wave voltage (modulation parameter), $m \cos (\Omega t)$ is the flicker voltage and $\Omega$ is the angular frequency of the amplitude modulation voltage. A flicker signal is generated to simulate with following parameters:

$u(t)=V_{m}[1+m a(t)] \cos \left(\omega_{0} t\right)$

That

$\omega_{0}=100 \pi \frac{\mathrm{rad}}{\mathrm{s}}, V_{m}=0.1 \mathrm{~V}$

$a(t)=\cos (\Omega t)+\frac{1}{3} \cos (3 \Omega t)+\frac{1}{5} \cos (5 \Omega t)$

When there is Flicker, $m=1$ and otherwise $m=0$. The desired signals are generated and simulated in Matlab environment and then analyzed in Wavelet field. All times presented in the rest of the article are generated randomly. All times are in seconds.

\subsection{Voltage Sag and Protrusion}

The main wavelet function $\mathrm{db} 4$ was used for analysis. It can be seen that the details of the first level are sufficient to detect the phenomena. For example, look at the voltage drop phenomenon in Figure 1. Figure 1(a) shows the perturbation signal and Figure 1(b) shows the details of the first level.

As we can see, the start and end times of the disturbance became very clear. For this particular example, the occurrence and termination times are 0.0248 and 0.0349 , respectively, and the program detects the times 0.0250 and 0.0352 , which is a good approximation. The actual error length is 0.0101 and the calculated length is 0.0102 , which indicates an error of $1 \%$ in calculating the error length.

Figure 2 shows a voltage swell. As we can see from Table 2, the actual and obtained times for the onset, end, and length of the perturbation are significantly closer.

So far, we have uncovered these two phenomena. If the standard deviation curve of the details is drawn at different levels, a distinction can be made between these two perturbations. Figure 3 shows the standard deviation curve of the high voltage sag and protrusion and a pure sine wave. We see that the maximum standard deviation of the coefficients in the voltage rise is greater than this value in the pure sine wave, while the maximum standard deviation of the coefficients in the voltage sag is less than its corresponding value in the pure sine wave. The parameters of this perturbation and the actual and obtained times are given in Table 2.

The accuracy of the results expressed in the program repetitions is also repeated. 
Table 1. Model of power quality perturbation

\begin{tabular}{|c|c|c|}
\hline $\begin{array}{c}\text { Power quality } \\
\text { perturbation }\end{array}$ & Model & Parameters \\
\hline Sinusoidal & $x(t)=\sin (\omega t)$ & \\
\hline Voltage Swell & $\begin{array}{c}x(t)=A\left(1+\alpha\left(u\left(t-t_{1}\right)-u\left(t-t_{2}\right)\right)\right) \sin (\omega t) \\
t_{1}<t_{2}, u(t)=\left\{\begin{array}{l}1, t \geq 0 \\
0, t<0\end{array}\right.\end{array}$ & $\begin{array}{l}0.1 \leq \alpha \leq 0.8 \\
T \leq t_{2}-t_{1} \leq 9 T\end{array}$ \\
\hline Voltage Sag & $x(t)=A\left(1-\alpha\left(u\left(t-t_{1}\right)-u\left(t-t_{2}\right)\right)\right) \sin (\omega t)$ & $\begin{array}{l}0.1 \leq \alpha \leq 0.9 \\
T \leq t_{2}-t_{1} \leq 9 T\end{array}$ \\
\hline Harmonic & $\begin{array}{r}x(t)=A\left(\alpha_{1} \sin (\omega t)+\alpha_{3} \sin (3 \omega t)+\right. \\
\left.\alpha_{5} \sin (5 \omega t)+\alpha_{7} \sin (7 \omega t)\right)\end{array}$ & $\begin{array}{l}0.05 \leq \alpha_{3} \leq 0.15,0.05 \leq \alpha_{5} \leq 0.15, \\
0.05 \leq \alpha_{7} \leq 0.15, \quad \sum \alpha_{i}^{2}=1\end{array}$ \\
\hline $\begin{array}{l}\text { Voltage swell with } \\
\text { Harmonic }\end{array}$ & $\begin{array}{l}x(t)=A\left(1-\alpha\left(u\left(t-t_{1}\right)-u\left(t-t_{2}\right)\right)\right) \\
\left(\alpha_{1} \sin (\omega t)+\alpha_{3} \sin (3 \omega t)+\alpha_{5} \sin (5 \omega t)\right.\end{array}$ & $\begin{array}{l}0.1 \leq \alpha \leq 0.9, T \leq t_{2}-t_{1} \leq 9 T \\
0.05 \leq \alpha_{3} \leq 0.15,0.05 \leq \alpha_{5} \leq 0.15, \\
\sum \alpha_{i}^{2}=1\end{array}$ \\
\hline $\begin{array}{l}\text { Voltage Sag with } \\
\text { Harmonic }\end{array}$ & $\begin{array}{l}x(t)=A\left(1+\alpha\left(u\left(t-t_{1}\right)-u\left(t-t_{2}\right)\right)\right) \\
\left(\alpha_{1} \sin (\omega t)+\alpha_{3} \sin (3 \omega t)+\alpha_{5} \sin (5 \omega t)\right.\end{array}$ & $\begin{array}{c}0.1 \leq \alpha \leq 0.9, T \leq t_{2}-t_{1} \leq 9 T \\
0.05 \leq \alpha_{3} \leq 0.15,0.05 \leq \alpha_{5} \leq 0.15 \\
\sum \alpha_{i}^{2}=1\end{array}$ \\
\hline
\end{tabular}

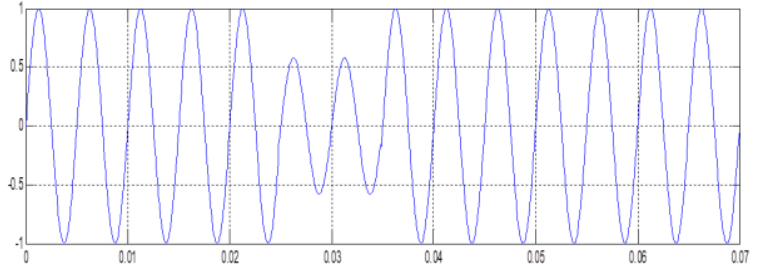

(a)

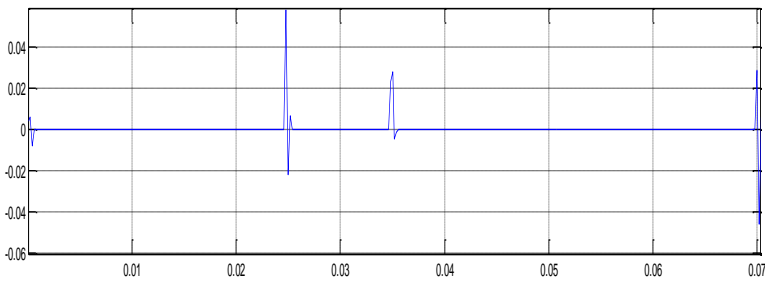

(b)

Figure 1. (a) An example of a voltage sag, (b) Details of the first level

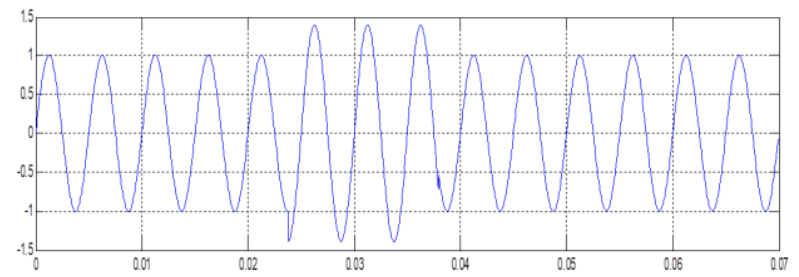

(a)

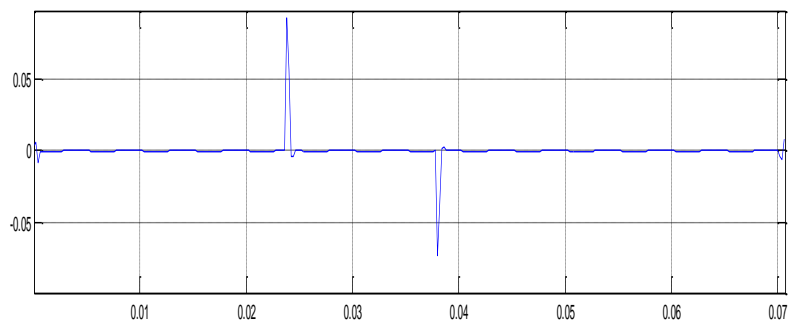

(b)

Figure 2. (a) A voltage swell, (b) The first level details
Table 2. The parameters of the voltage swell

\begin{tabular}{|c|c|c|c|}
\hline $\begin{array}{c}\text { Calculated } \\
\text { Start Time }\end{array}$ & $\begin{array}{c}\text { Calculated } \\
\text { End Time }\end{array}$ & $\begin{array}{c}\text { Calculated } \\
\text { Length }\end{array}$ & $\begin{array}{c}\text { Error } \\
\%\end{array}$ \\
\hline 0.0240 & 0.0382 & 0.0142 & 0.5351 \\
\hline $\begin{array}{c}\text { Real Time } \\
\text { Start }\end{array}$ & $\begin{array}{c}\text { Real Time } \\
\text { End }\end{array}$ & $\begin{array}{c}\text { Voltage Sag } \\
\text { Range }\end{array}$ & $\begin{array}{c}\text { Actual } \\
\text { Length }\end{array}$ \\
\hline 0.0238 & 0.0380 & 1.3934 & 0.0141 \\
\hline
\end{tabular}

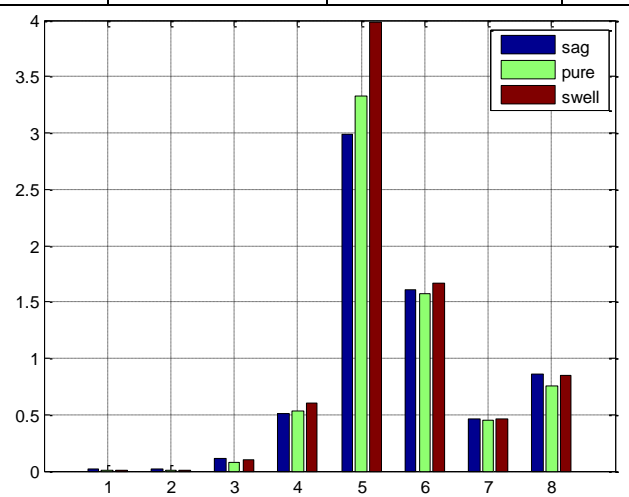

Figure 3. Standard deviation curve at different levels

\subsection{Voltage Sag with Harmonic, Voltage Rise with Harmonic}

Again, the db4 function is used in this section. Figure 4 shows a voltage sag in the presence of a harmonic perturbation.

Figure 5 shows a harmonic voltage rise. Actual and calculated start and end times as well as actual and calculated error lengths are given in Table 3. A small error of $0.8547 \%$ also confirms the correctness of the proposed algorithm. The accuracy shown demonstrates the advantage of wavelet transform in investigating this perturbation. 


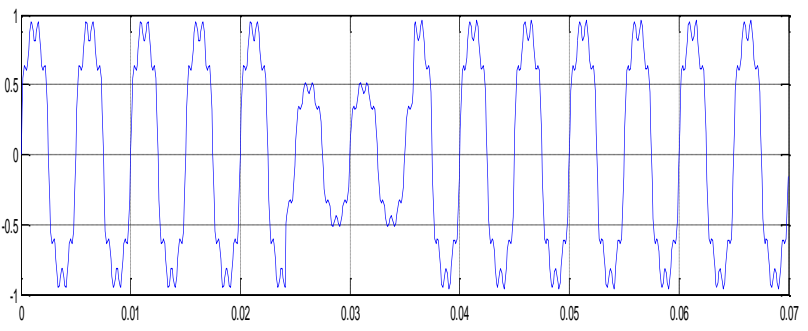

(a)

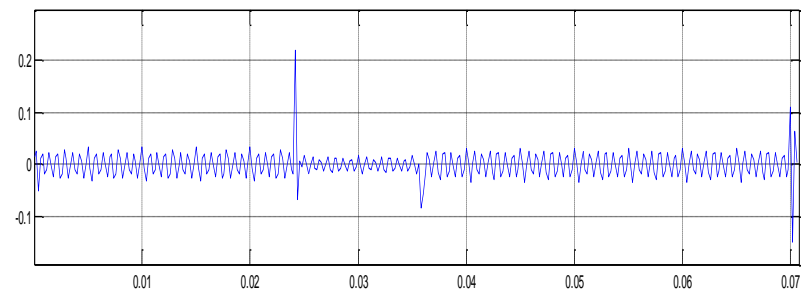

(b)

Figure 4. (a) A recess with a harmonic, (b) The first level details

Table 3. The parameters of the harmonica sag phenomenon

\begin{tabular}{|c|c|c|c|}
\hline $\begin{array}{c}\text { Calculated } \\
\text { Start Time }\end{array}$ & $\begin{array}{c}\text { Calculated } \\
\text { End Time }\end{array}$ & $\begin{array}{c}\text { Calculated } \\
\text { Length }\end{array}$ & $\begin{array}{c}\text { Error } \\
\text { \% }\end{array}$ \\
\hline 0.0244 & 0.0360 & 0.0116 & 0.8547 \\
\hline $\begin{array}{c}\text { Real Time } \\
\text { Start }\end{array}$ & $\begin{array}{c}\text { Real Time } \\
\text { End }\end{array}$ & $\begin{array}{c}\text { Voltage Sag } \\
\text { Range }\end{array}$ & $\begin{array}{c}\text { Actual } \\
\text { Length }\end{array}$ \\
\hline 0.0243 & 0.0359 & 0.5398 & 0.0117 \\
\hline $\mathrm{h}_{3}=0.1417$ & $\mathrm{~h}_{5}=0.0786$ & \multicolumn{3}{|c|}{$\mathrm{h}_{7}=0.1257$} \\
\hline
\end{tabular}

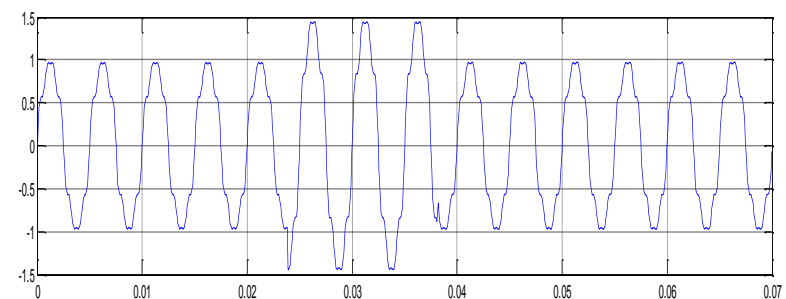

(a)

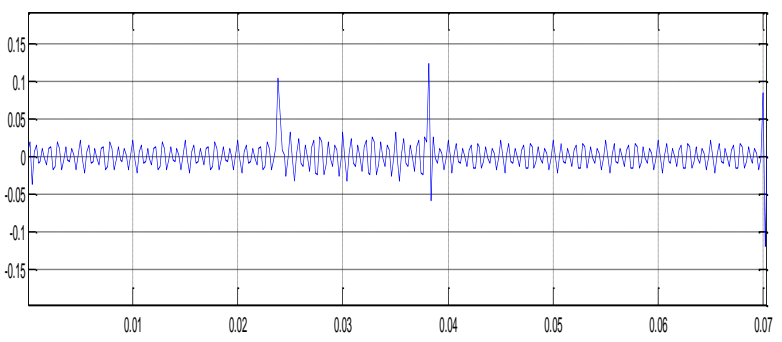

(b)

Figure 5. (a) Voltage swell with Harmonic (b) The first level details

The harmonic addition does not change what was said about the standard deviation of the detail coefficients in the previous section, and it still works to distinguish between indentations and ridges. That is, the maximum standard deviation of the details at different levels in the voltage sag is less than the pure sine wave, while this value will be greater in the voltage swell than the sine wave.

\subsection{Flicker}

Suppose there is a voltage flicker sample similar to following equation.
$u(t)=V_{m}[1+m a(t)] \cos \left(\omega_{0} t\right)$

That

$$
\begin{aligned}
& \omega_{0}=100 \pi \frac{\mathrm{rad}}{\mathrm{s}}, V_{m}=0.1 \mathrm{~V} \\
& a(t)=\cos (\Omega t)+\frac{1}{3} \cos (3 \Omega t)+\frac{1}{5} \cos (5 \Omega t)
\end{aligned}
$$

The signal is simulated and written to the wavelet. By comparing different wavelets in Matlab, db24 was selected as a suitable wavelet. By observing the details and approximations at different levels, it can be seen that the details of the first level have the ability to detect the start and end times of this phenomenon (Figure 6). The various parameters of this perturbation are given in Table 4. A negligible error of $0.29 \%$ indicates the efficiency of this algorithm in voltage flicker detection.

Table 4. Parameters of the phenomenon of voltage swell with harmonic

\begin{tabular}{|c|c|c|c|}
\hline $\begin{array}{c}\text { Calculated } \\
\text { Start Time }\end{array}$ & $\begin{array}{c}\text { Calculated } \\
\text { End Time }\end{array}$ & $\begin{array}{c}\text { Calculated } \\
\text { Length }\end{array}$ & $\begin{array}{c}\text { Error } \\
\%\end{array}$ \\
\hline 0.0384 & 0.0240 & 0.0144 & 0.7100 \\
\hline $\begin{array}{c}\text { Real Time } \\
\text { Start }\end{array}$ & $\begin{array}{c}\text { Real Time } \\
\text { End }\end{array}$ & $\begin{array}{c}\text { Voltage Sag } \\
\text { Range }\end{array}$ & $\begin{array}{c}\text { Actual } \\
\text { Length }\end{array}$ \\
\hline 390.02 & 0.0382 & 1.4869 & 0.0143 \\
\hline $\mathrm{h}_{3}=0.0584$ & $\mathrm{~h}_{5}=0.0900$ & \multicolumn{3}{|c|}{$\mathrm{h}_{7}=0.0760$} \\
\hline
\end{tabular}

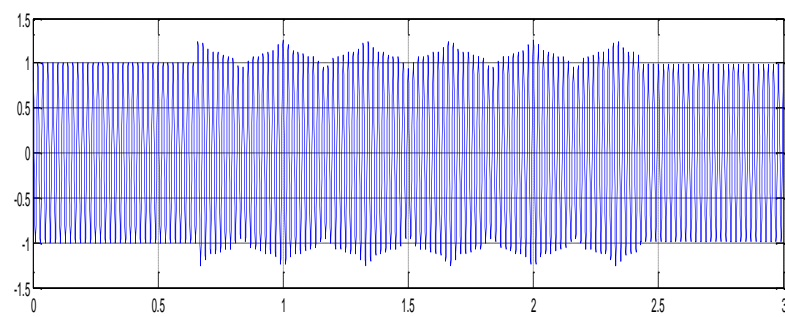

(a)

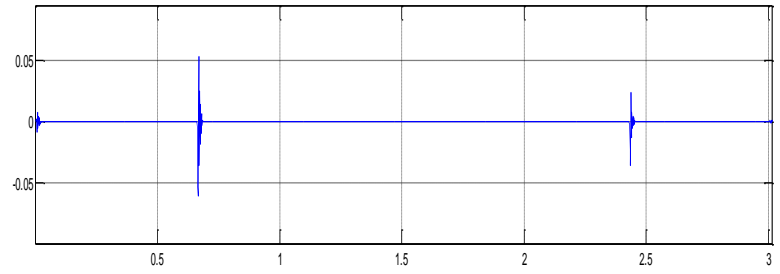

(b)

Figure 6. (a) An example of a voltage flicker, (b) Details in the first level

\section{CONCLUSION}

This article presents a suggestion for detecting and locating power quality phenomena. The perturbations of voltage dip, voltage swell, harmonic dip, harmonic swell and flicker are simulated and plotted in the Wavelet field. The ability of this transform to decompose waveforms into different levels of detail and approximation made it possible to detect these phenomena. The start and end times and the length of the error are obtained with good accuracy. Also, with the help of standard deviation of detail coefficients at different levels, a distinction is made between the two phenomena of sag and voltage swell. 


\section{REFERENCE}

[1] O. P. Mahela, B. Khan, H. H. Alhelou, and S. Tanwar, "Assessment of power quality in the utility grid integrated with wind energy generation," IET Power Electronics, vol. 13, pp. 2917-2925, 2020.

[2] O. P. Mahela, B. Khan, H. H. Alhelou, and P. Siano, "Power quality assessment and event detection in distribution network with wind energy penetration using stockwell transform and fuzzy clustering," IEEE Transactions on Industrial Informatics, vol. 16, pp. 6922-6932, 2020.

[3] H. Shokouhandeh, M. Ghaharpour, H. G. Lamouki, Y. R. Pashakolaei, F. Rahmani, and M. H. Imani, "Optimal Estimation of Capacity and Location of Wind, Solar and Fuel Cell Sources in Distribution Systems Considering Load Changes by Lightning Search Algorithm," in 2020 IEEE Texas Power and Energy Conference (TPEC), 2020, pp. 1-6.

[4] C. Diaz, F. Ruiz, and D. Patino, "Analysis of water booster pressure systems as dispatchable loads in smart-grids," in 2017 IEEE PES Innovative Smart Grid Technologies Conference Europe (ISGTEurope), 2017, pp. 1-6.

[5] H. Haggi, W. Sun, and J. Qi, "Multi-Objective PMU Allocation for Resilient Power System Monitoring," in 2020 IEEE Power \& Energy Society General Meeting (PESGM), 2020, pp. 1-5.

[6] S. Khazaee, M. Hayerikhiyavi, S. M. Kouhsari, "A Direct-Based Method for Real-Time Transient Stability Assessment of Power Systems", CRPASE Vol. 06(02), 108-113, June 2020.

[7] M. Bajaj and A. K. Singh, "Grid integrated renewable DG systems: a review of power quality challenges and state-of-the-art mitigation techniques," International Journal of Energy Research, vol. 44, pp. 26-69, 2020.

[8] H. Shokouhandeh and M. Jazaeri, "An enhanced and auto-tuned power system stabilizer based on optimized interval type-2 fuzzy PID scheme," International Transactions on Electrical Energy Systems, vol. 28, p. e2469, 2018.

[9] W. Qiao and Z. Yang, "Forecast the electricity price of US using a wavelet transform-based hybrid model," Energy, vol. 193, p. 116704, 2020.

[10] S. Kumar, R. Kumar, R. P. Agarwal, and B. Samet, "A study of fractional Lotka-Volterra population model using Haar wavelet and Adams-Bashforth-Moulton methods," Mathematical Methods in the Applied Sciences, vol. 43, pp. 55645578, 2020.

[11] S. K. Khare, V. Bajaj, and G. Sinha, "Adaptive Tunable Q Wavelet Transform-Based Emotion Identification," IEEE transactions on instrumentation and measurement, vol. 69, pp. 9609-9617, 2020.

[12] M. Asadi, H. Shokouhandeh, F. Rahmani, S. M. Hamzehnia, M. N. Harikandeh, H. G. Lamouki, et al., "Optimal placement and sizing of capacitor banks in harmonic polluted distribution network," in 2021 IEEE Texas Power and Energy Conference (TPEC), 2021, pp. 1-6.

[13] F. Z. Dekhandji, "Detection of power quality disturbances using discrete wavelet transform," in 2017 5th International Conference on Electrical Engineering-Boumerdes (ICEE-B), 2017, pp. 1-5.
R. Kumar and H. O. Bansal, "Hardware in the loop implementation of wavelet based strategy in shunt active power filter to mitigate power quality issues," Electric Power Systems Research, vol. 169, pp. 92 104, 2019.

[15] H. Shokouhandeh, M. Jazaeri, and M. Sedighizadeh, "On-time stabilization of single-machine power system connected to infinite bus by using optimized fuzzy-PID controller," in 2014 22nd Iranian Conference on Electrical Engineering (ICEE), 2014, pp. 768-773.

[16] B. Eristi, O. Yildirim, H. Eristi, and Y. Demir, "A new embedded power quality event classification system based on the wavelet transform," International Transactions on Electrical Energy Systems, vol. 28, p. e2597, 2018.

[17] H. Huang, R. He, Z. Sun, and T. Tan, "Waveletsrnet: A wavelet-based cnn for multi-scale face super resolution," in Proceedings of the IEEE International Conference on Computer Vision, 2017, pp. 1689-1697. 